\title{
Analisis Perbandingan Latency Hasil Patch Test dengan Latency Real Titik Fiks Perum pada Survei Hidrografi (Studi Kasus: Pelabuhan Tanjung Benoa Bali)
}

\author{
FAKHRI RIZKIAN, NI MADE RAI RATIH CAHYA PERBANI
}

\author{
Jurusan Teknik Geodesi \\ FTSP - Institut Teknologi Nasional, Bandung \\ Email: fakhrizkian@gmail.com
}

\begin{abstract}
ABSTRAK
Latency merupakan perbedaan yang terjadi akibat ketidaksinkronan waktu antara alat perekaman posisi horizontal dengan kedalaman laut. Masalah latency muncul ketika lokasi pengukuran berkarakteristik slope. Latency real bersifat individual untuk setiap titik fiks perum, sementara latency hasil patch test sepanjang jalur. Tujuan dari penelitian ini adalah untuk mengetahui sejauh mana koreksi latency hasil teknik patch test dapat memberikan model topografi di sepanjang jalur pengukuran yang sesuai dengan model topografi dengan latency real. Koreksi kedalaman akibat latency diperoleh menggunakan fungsi slope, kecepatan kapal, dan latency untuk diterapkan baik pada latency hasil patch test maupun latency real. Tren model topografi di Pelabuhan Tanjung Benoa, Bali dengan kecepatan lebih rendah (rata-rata 4,2 $\mathrm{m} /$ detik) lebih mewakili kondisi topografi sebenarnya. Nilai deviasi standar untuk kecepatan lebih rendah sebesar $\pm 0,16 \mathrm{~m}$ dan untuk kecepatan lebih tinggi (rata-rata 6,2 $\mathrm{m} /$ detik) sebesar $\pm 0,2 \mathrm{~m}$ yang masih memenuhi standar ketelitian kedalaman menurut SNI sebesar 0,28 m.
\end{abstract}

Kata kunci: latency, patch test, model topografi

\begin{abstract}
Latency is a difference occurred while horizontal position and depth measurement is taken unsynchronously. The bigger slope of sea bottom topography in measurement area, the bigger problem of latency that arise. Real latency in individualited for each sounding fixed point, while patch test gives an along track latency. This research is schemed for finding whether the correction of latency from patch test ensure the topography model along measurement track can be fitted with the model from real latency. Depth correction for latency is calculated as a function of slope, vessel speed, and latency. It is applied for both of latency from patch test and the real latency. The trend of topography model in Tanjung Benoa Port, Bali from measurement with slower speed $(4,2 \mathrm{~m} / \mathrm{sec}$ average speed) more represent the actual topography. Standard deviation for measurement with slower speed is $\pm 0,16 \mathrm{~m}$; while for faster speed $(6,2 \mathrm{~m} / \mathrm{sec}$ average speed) is $\pm 0,2 \mathrm{~m}$. Both of the vessel speed still fullfil depth accuracy standard of SNI, that is under $0,28 \mathrm{~m}$.
\end{abstract}

Keywords: latency, patch test, topography model 


\section{PENDAHULUAN}

Menurut Burnett (2013), latency merupakan perbedaan yang terjadi akibat ketidaksinkronan waktu pada alat perekaman posisi horizontal menggunakan GPS dan alat pengukur kedalaman laut (echosounder) ketika melakukan survei hidrografi. Masalah latency muncul ketika pengukuran dilakukan pada suatu lokasi yang memiliki karakteristik slope (kemiringan) pada topografi dasar laut, slope yang besar akan semakin mempengaruhi perubahan posisi kedalaman titik. Perubahan posisi kedalaman titik tersebut akan menyebabkan kesalahan informasi kedalaman yang diperoleh, di mana kesalahan tersebut akan mempengaruhi model topografi dasar laut yang dibentuk. Untuk itu perlu dilakukan suatu teknik pemberian koreksi akibat latency, salah satu di antaranya adalah patch test. Menurut Burnett (2013), patch test merupakan serangkaian prosedur pengambilan data pada survei hidrografi dengan melakukan analisis statistik pada suatu kumpulan data untuk menentukan besaran kesalahan pada sistem peralatan multibeam echosounder di mana patch test ini dirancang secara tepat untuk menentukan konfigurasi peralatan multibeam echosounder. Menurut Razali dkk. (2007), beberapa prosedur yang harus dipersiapkan untuk menentukan latency pada teknik patch test, yaitu dua jalur pemeruman dengan arah yang sama, menggunakan kecepatan kapal yang berbeda, sebaiknya satu jalur harus menggunakan kecepatan yang minimum dan satu jalur lainnya menggunakan dua kali kecepatan dari jalur yang pertama pada daerahdaerah yang memiliki slope pada topografi dasar lautnya.

Penelitian Seube dkk. (2015) membahas mengenai kesalahan latency yang terjadi dan bagaimana menentukan estimasi besarnya kesalahan yang terjadi akibat kesalahan latency kemudian memodelkan kesalahan tersebut menggunakan perangka lunak R2SONIC 2022. Besarnya estimasi kesalahan latency tersebut didasarkan pada metode kuadrat terkecil untuk menemukan parameter model dan menganalisis tren statistik yang terjadi pada sekumpulan data patch test. Parameter yang digunakan dalam menghitung estimasi besarnya latency tersebut terdiri atas kecepatan kapal, slope, dan perbedaan waktu perekaman posisi horizontal dan pengukur kedalaman. Hasil penelitian tersebut berupa kalibrasi otomatis latency menggunakan model matematis yang didasarkan pada statistik yang ditunjukkan berdasarkan plotting parameter kedalaman (Z) dan posisi horizontal $(X, Y)$. Lokasi patch test ini berada di Pelabuhan Brest, Perancis yang memiliki slope topografi dasar laut yang bervariasi.

Di samping patch test menurut Burnett (2013), teknik pemberian koreksi akibat latency dapat menggunakan peralatan Ports, Protocols, Services (PPS) dalam sinkronisasi waktu pada alat perekaman posisi horizontal dan alat pengukur kedalaman. Hal tersebut dapat dilakukan sebelum melakukan pengukuran dan pada teknik ini kesalahan latency langsung diperbaiki sehingga sudah tidak diperhitungkan dalam data pengukuran. Teknik yang lain lagi untuk memberi koreksi akibat latency adalah menghitung latency real titik fiks perum dengan berbagai parameter, antara lain: slope topografi dasar laut, dan besaran displacement posisi titik kedalaman. Proses hitungan latency real titik fiks perum ini mempertimbangkan perbedaan kecepatan kapal yang terjadi dari setiap titik pemeruman. Pada teknik patch test 
juga digunakan kecepatan yang bervariasi, tetapi koreksi akibat latency pada teknik ini diwakili oleh satu nilai untuk sepanjang jalur pengukuran karena yang dipertimbangkan adalah displacement sepanjang jalur. Koreksi latency pada survei hidrografi di Pelabuhan Tanjung Benoa, Bali tahun 2016 diperoleh melalui proses menggunakan perangkat lunak Hypack Hysweep 2015. Untuk mengetahui sejauh mana koreksi latency hasil patch test ini dapat mewakili kondisi topografi dasar laut yang sebenarnya, maka pada penelitian ini hasil koreksi tersebut dibandingkan dengan hasil koreksi menggunakan latency real titik fiks perum yang bukan menggunakan latency sepanjang jalur, tetapi latency di setiap titik. Hasil dari perbandingan diharapkan dapat memberikan gambaran mengenai keterandalan koreksi hasil patch test untuk diterapkan pada daerah survei sehingga dapat diberikan rekomendasi-rekomendasi dalam rangka mendapatkan hasil survei yang memenuhi standar.

Latency real titik fiks perum bersifat individual untuk setiap titik pemeruman, sementara pada teknik patch test hasil koreksi diterapkan di sepanjang jalur pengukuran sehingga akan lebih sederhana di dalam penerapannya. Namun, hasil yang diperoleh seharusnya dapat menjamin sinkronisasi antara waktu pengukuran horizontal dengan kedalaman sehingga dapat mewakili topografi dasar laut sebenarnya. Latency real titik fiks perum bersifat individual sehingga diasumsikan lebih detail mewakili topografi dasar laut. Oleh karena itu, koreksi akibat latency hasil patch test akan dibandingkan dengan latency real titik fiks perum. Berdasarkan penjelasan mengenai teknik-teknik untuk memberikan koreksi akibat latency yang terjadi maka rumusan masalah pada penelitian ini adalah : "Apakah koreksi latency hasil teknik patch test di lokasi Pelabuhan Tanjung Benoa, Bali dapat memberikan model topografi di sepanjang jalur pengukuran yang sesuai dengan model topografi dengan latency real titik fiks perum?"

Tujuan dari penelitian ini adalah untuk mengetahui sejauh mana koreksi latency hasil teknik patch test di lokasi Pelabuhan Tanjung Benoa, Bali dapat memberikan model topografi di sepanjang jalur pengukuran yang sesuai dengan model topografi dengan latency real titik fiks perum.

Batasan masalah pada penelitian ini dalam rangka mengetahui sejauh mana koreksi latency hasil teknik patch test dapat menjamin sinkronisasi antara waktu pengukuran posisi horizontal dan kedalaman di lokasi Pelabuhan Tanjung Benoa, Bali antara lain yaitu data kedalaman laut sudah diberi koreksi surutan dan koreksi kecepatan gelombang suara dan koreksi faktor pitch, roll dan yaw dari kapal, data pengukuran horizontal diasumsikan sebagai data fixed sehingga data kedalaman yang disesuaikan dengan data pengukuran horizontal, data hasil pengukuran horizontal dan kedalaman multibeam patch test hanya digunakan satu jalur (singlebeam), perubahan pada topografi dasar laut antar titik diasumsikan sebagai garis yang lurus (linier), kecepatan kapal di jalur patch test tetap (tidak mengalami percepatan) pada saat displacement terjadi akibat ketidaksinkronan waktu pada alat pengukuran horizontal dan alat pengukur kedalaman, model topografi yang dihasilkan dari latency real titik fiks perum diasumsikan sebagai model topografi yang sebenarnya. 


\section{METODOLOGI}

Lokasi pada penelitian ini berada pada posisi $08^{\circ} 50^{\prime} 57^{\prime \prime}$ LS dan $115^{\circ} 15^{\prime} 09^{\prime \prime}$ BT di Kabupaten Badung, Kecamatan Kuta Selatan, Provinsi Bali, yaitu di Pelabuhan Tanjung Benoa. Data yang digunakan dalam penelitian ini berupa data hasil pengukuran sepanjang jalur patch test yang berisi informasi posisi horizontal $(\mathrm{X}, \mathrm{Y})$ pada waktu GPS, informasi kedalaman (Z) dari waktu echoosunder dan kecepatan kapal yang digunakan. Sampel inventarisasi data pada sepanjang jalur pengukuran patch test dapat dilihat pada Tabel 1.

Tabel 1. Sampel Inventarisasi Data Sepanjang Jalur Pengukuran Patch Test

\begin{tabular}{|c|c|c|c|c|c|c|c|c|c|c|c|}
\hline \multirow{2}{*}{ No } & \multirow{2}{*}{ Titik } & \multicolumn{3}{|c|}{ Posisi } & \multicolumn{3}{|c|}{ Waktu GPS } & \multicolumn{3}{|c|}{ Waktu Echosounder } & \multirow{2}{*}{$\begin{array}{r}\text { Kecepatan } \\
\text { (m/detik) }\end{array}$} \\
\hline & & $\mathrm{x}$ & $\mathbf{Y}$ & $Z$ & Jam & Menit & Detik & Jam & Menit & Detik & \\
\hline 1 & P1 & 305507.49 & 9031434.04 & 12.05 & 14 & 45 & 22.599 & 14 & 45 & 22.618 & 5.9 \\
\hline 2 & P2 & 305507.28 & 9031434.61 & 12.18 & 14 & 45 & 22.398 & 14 & 45 & 22.417 & 5.9 \\
\hline 3 & P3 & 305507.07 & 9031435.18 & 12.21 & 14 & 45 & 22.199 & 14 & 45 & 22.216 & 5.9 \\
\hline 4 & P4 & 305506.86 & 9031435.75 & 12.45 & 14 & 45 & 22 & 14 & 45 & 22.04 & 5.9 \\
\hline 5 & P5 & 305506.63 & 9031436.31 & 12.72 & 14 & 45 & 21.8 & 14 & 45 & 21.82 & 5.8 \\
\hline 6 & P6 & 305506.16 & 9031437.39 & 12.85 & 14 & 45 & 21.599 & 14 & 45 & 21.614 & 5.9 \\
\hline 7 & P7 & 305505.92 & 9031438.03 & 13.16 & 14 & 45 & 21.398 & 14 & 45 & 21.398 & 5.9 \\
\hline 8 & P8 & 305505.70 & 9031438.65 & 13.31 & 14 & 45 & 21.199 & 14 & 45 & 21.211 & 6.1 \\
\hline 9 & P9 & 305505.47 & 9031439.24 & 13.56 & 14 & 45 & 21 & 14 & 45 & 21.012 & 6.1 \\
\hline 10 & P10 & 305505.27 & 9031439.82 & 13.66 & 14 & 45 & 20.8 & 14 & 45 & 20.811 & 6 \\
\hline
\end{tabular}

Metodologi penelitian dalam analisis perbandingan latency hasil patch test dengan latency real titik fiks perum pada survei hidrografi ini terbagi menjadi dua, yaitu untuk menganalisis slope pada topografi dasar laut untuk mengetahui terpenuhi tidaknya untuk lokasi patch test pada Gambar 1.1 dan untuk menerapkan koreksi kedalaman akibat latency pada data pengukuran dilihat Pada Gambar 1.2.

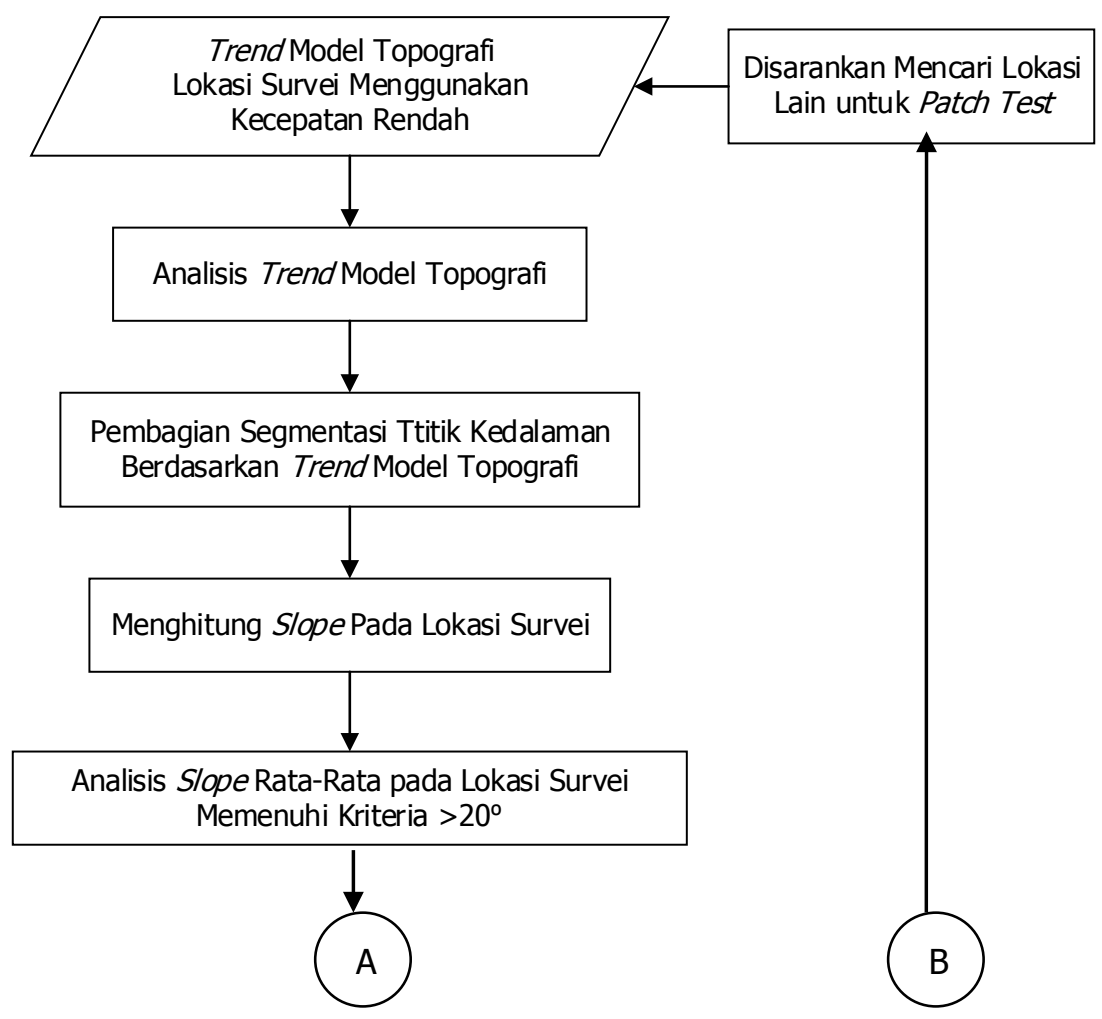

Reka Geomatika - 35 




Gambar 1. Metodologi Penelitian Kriteria Lokasi Patch Test

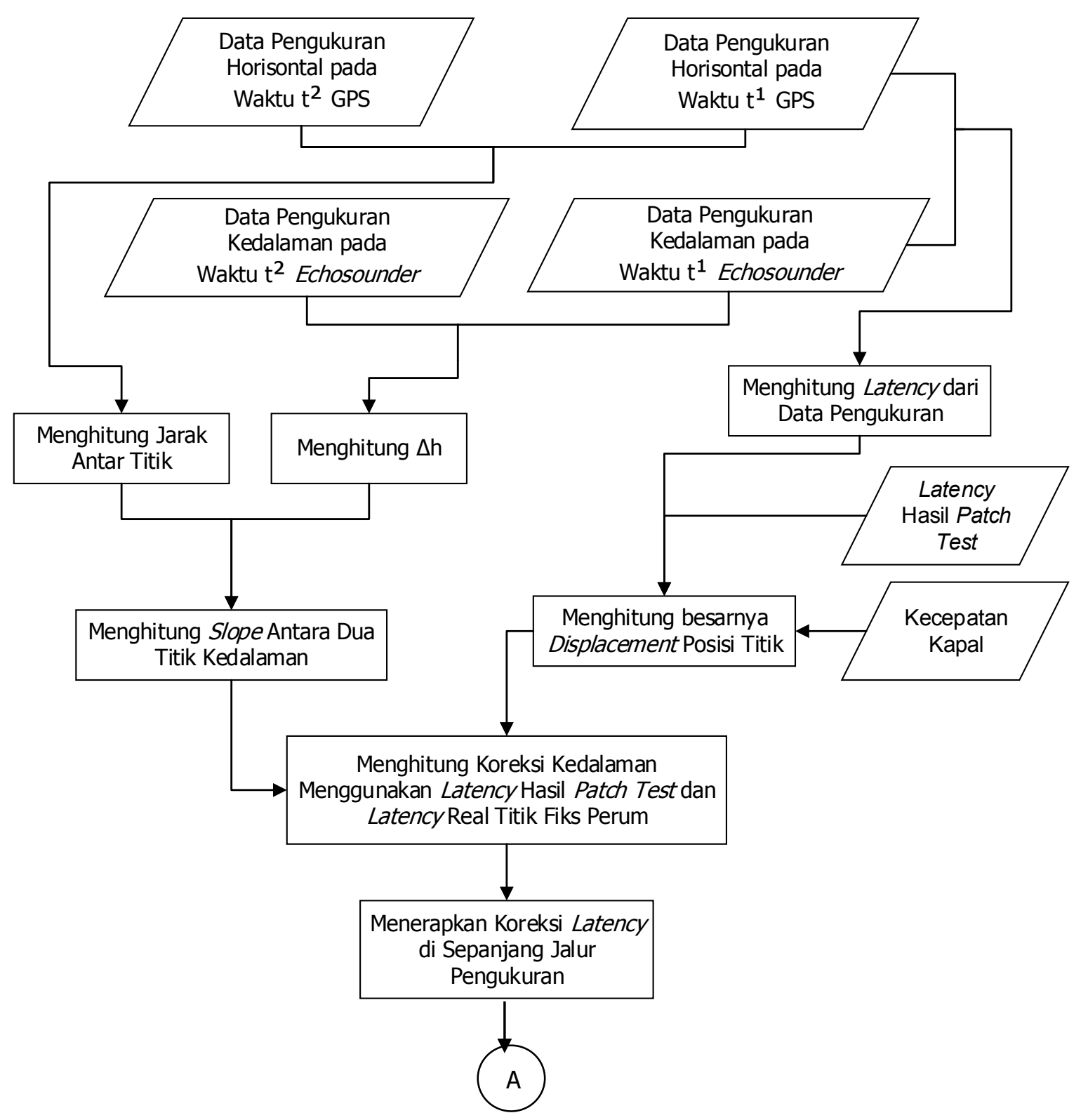

Reka Geomatika - 36 




Gambar 2. Metodologi Penelitian Menerapkan Koreksi Kedalaman Akibat Latency

\section{HASIL DAN PEMBAHASAN}

\subsection{Slope Pada Topografi Dasar Laut}

Menurut Burnett (2013), kriteria lokasi yang diperlukan untuk melakukan patch test sebaiknya pada lokasi yang memiliki slope minimal $20^{\circ}$ agar diketahui seberapa besar pengaruh pergeseran posisi titik kedalaman akibat latency. Latency akan menyebabkan pergeseran pada model topografi dasar laut akibat informasi kedalaman yang diperoleh tidak sinkron dengan data horizontal. Menurut Lekkerkerk (2006), pada kondisi topografi yang relatif datar kesalahan latency bisa terjadi, tetapi hal tersebut tidak terlalu berpengaruh karena informasi kedalaman yang diperoleh relatif sama. Kesalahan latency akan sangat berpengaruh pada kondisi topografi dasar laut yang memiliki slope. Untuk menguji slope (kemiringan) di lokasi patch test pada survei di Pelabuhan Tanjung Benoa, Bali digunakan hasil tren model topografi dengan kecepatan lebih rendah rata-rata 4,2 $\mathrm{m} /$ detik dengan asumsi kedalaman yang diperoleh lebih detail dibandingkan hasil model tren topografi dengan kecepatan yang lebih tinggi. Untuk mengetahui apakah lokasi tersebut memenuhi kriteria patch test maka dilakukan proses hitungan slope berdasarkan tren topografi dan dibagi dalam beberapa segmen yang memiliki kedalaman bervariasi untuk dihitung apakah lokasi survei memenuhi syarat untuk dilakukan patch test. Tren model topografi jalur pengukuran yang menggunakan kecepatan rendah dapat dilihat pada Gambar 1. 
Permukaan Laut

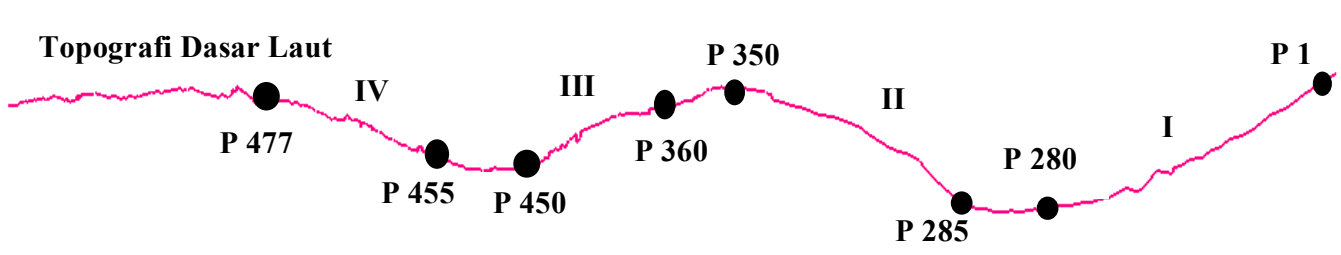

Gambar 1. Segmentasi Kedalaman pada Slope Topografi Dasar Laut

Variasi kedalaman tersebut digunakan untuk menghitung besaran slope pada topografi dasar laut yang dibagi dalam empat segmen kedalaman berdasarkan kedalaman yang memiliki perbedaan nilai cukup signifikan. Setelah diketahui segmentasi kedalaman yang digunakan maka dapat dihitung slope antar titik pada empat segmen kedalaman tersebut diperoleh hasil hitungan yang dapat dilihat pada Tabel 1.

Tabel 1. Hasil Hitungan Slope Lokasi Patch Test di Pelabuhan Tanjung Benoa Bali

\begin{tabular}{|c|c|c|c|c|}
\hline No & Selang & Jarak (m) & $\Delta \mathbf{d}(\mathbf{m})$ & Slope $\mathbf{(}^{\mathbf{}}$ ) \\
\hline 1 & P 1 - P 280 & 30,70 & $-12,66$ & $-22,41$ \\
\hline 2 & P 285 - P 350 & 29,79 & 12,47 & 22,71 \\
\hline 3 & P 360 - P 450 & 21,95 & $-9,86$ & $-24,19$ \\
\hline 4 & P 455 - P 477 & 22,78 & 9,45 & 22,53 \\
\hline
\end{tabular}

Karakteristik lokasi survei di Pelabuhan Tanjung Benoa, Bali memiliki rata-rata slope sebesar $23^{\circ}$. Slope terbesar memiliki nilai $-24,19^{\circ}$, sedangkan slope terkecil sebesar $22,41^{\circ}$. Slope dengan nilai negatif dan positif berfungsi untuk menunjukkan variasi kedalaman pada topografi dasar laut. Nilai slope negatif menunjukkan kecenderungan tren topografi dasar laut menurun ke arah yang memiliki nilai kedalaman semakin besar, sedangkan nilai slope positif menunjukkan kecenderungan tren topografi dasar laut naik ke arah yang memiliki nilai kedalaman semakin rendah. Berdasarkan hasil hitungan slope topografi dasar laut pada empat segmen kedalaman tersebut, maka slope pada lokasi survei di Pelabuhan Tanjung Benoa, Bali memenuhi syarat menurut kriteria Burnett (2013) untuk digunakan sebagai lokasi patch test. Artinya topografi yang dimiliki dapat digunakan untuk menunjukkan terjadinya latency.

\subsection{Perbandingan Tren Model Topografi}

Berdasarkan tahapan yang dilakukan untuk mengetahui koreksi akibat latency terhadap data pengukuran pada lokasi survei di Pelabuhan Tanjung Benoa, Bali maka diperoleh kedalaman yang sudah diberi koreksi akibat latency menggunakan teknik patch test dan latency real titik fiks perum yang kemudian digambarkan untuk mengetahui tren model topografi dasar laut yang dibentuk di sepanjang dua jalur pengukuran. Terdapat dua jalur pengukuran menggunakan kecepatan yang berbeda, 
pada jalur yang menggunakan kecepatan lebih tinggi dengan rata-rata 6,2 m/detik, sedangkan jalur pengukuran lainnya menggunakan kecepatan yang lebih rendah dengan rata-rata 4,2 $\mathrm{m} /$ detik. Perbedaan kecepatan tersebut akan mempengaruhi besaran kesalahan latency yang terjadi yang berakibat pada besaran displacement posisi titik kedalaman. Tren model topografi dasar laut pada jalur pengukuran yang menggunakan kecepatan yang bervariasi dengan rata-rata 6,2 $\mathrm{m} /$ detik dapat dilihat pada Gambar 2.

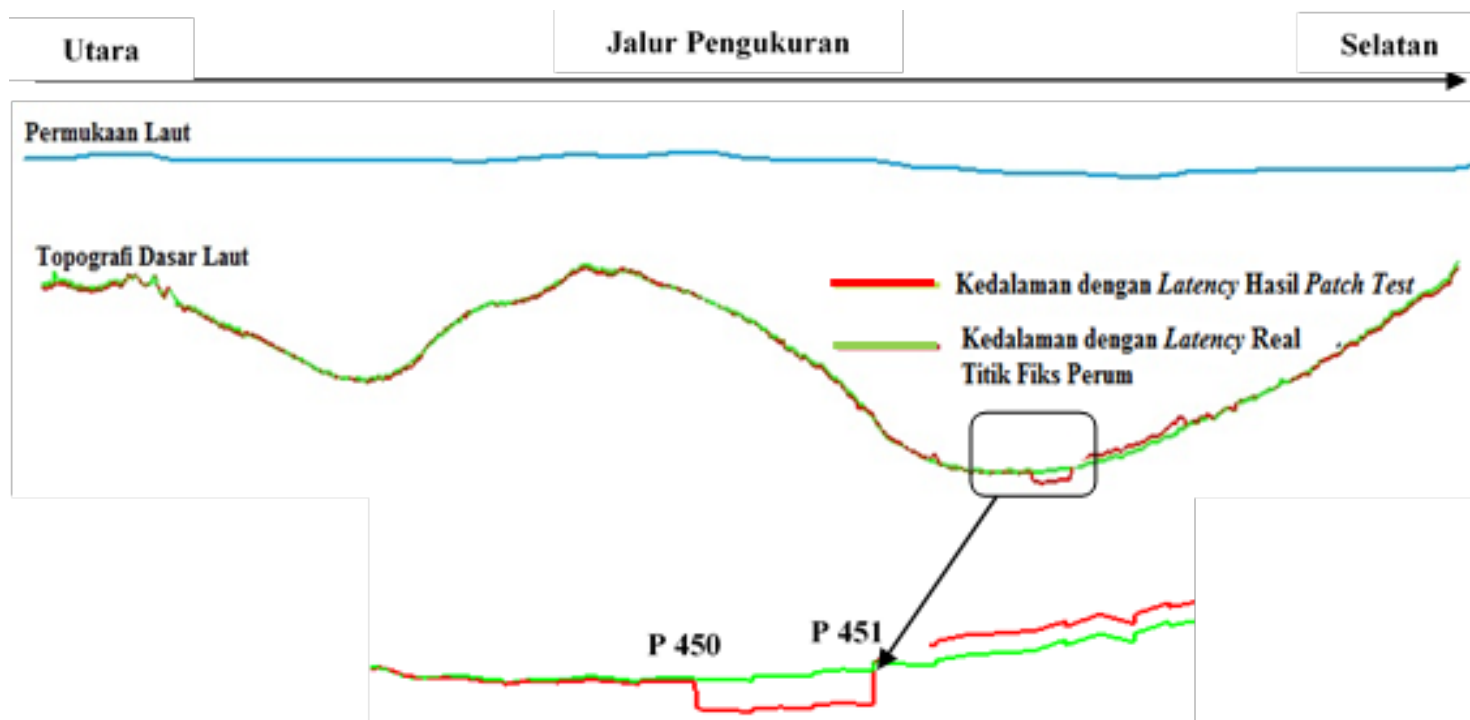

Gambar 2. Tren Model Topografi Menggunakan Kecepatan Rata-rata 6,2 m/detik

Berdasarkan Gambar 2 tren model topografi yang dibentuk dari kedalaman hasil koreksi akibat latency pada sepanjang jalur pengukuran menggunakan teknik patch test dan latency real titik fiks perum di lokasi Tanjung Benoa, Bali secara keseluruhan memiliki nilai kedalaman yang relatif tidak berbeda jauh. Tren model topografi dasar laut yang dibentuk dari kedalaman hasil koreksi akibat latency hasil patch test pada sepanjang jalur pengukuran dan latency antar titik fiks perum sama, tetapi muncul juga beberapa perbedaan informasi kedalaman, yaitu yang terjadi pada titik $P 450$ dan $P$ 451. Kedua titik tersebut memiliki nilai kedalaman sebesar $25 \mathrm{~m}$ menggunakan kecepatan yang digunakan sebesar lebih kurang 6,2 m/detik dengan latency sebesar 0,1 detik maka terjadi displacement di kedua titik tersebut sebesar 0,7 m dan 0,6 m. Perbedaan kedalaman yang cukup signifikan pada jalur pengukuran dengan kecepatan 6,2 m/detik sebesar 0,8 m terjadi pada tiitk dengan kedalaman $25 \mathrm{~m}$. Hal tersebut menunjukkan bahwa penggunaan kecepatan tinggi pada jalur pengukuran akan mempengaruhi informasi kedalaman yang diperoleh. Pada kondisi topografi dasar laut yang memiliki slope penggunaan kecepatan lebih rendah merupakan salah satu teknik agar dapat menimalisir kesalahan akibat latency. Tren model topografi pada jalur pengukuran dengan menggunakan kecepatan lebih rendah dengan ratarata 4,2 m/detik dapat dilihat pada Gambar 3. 


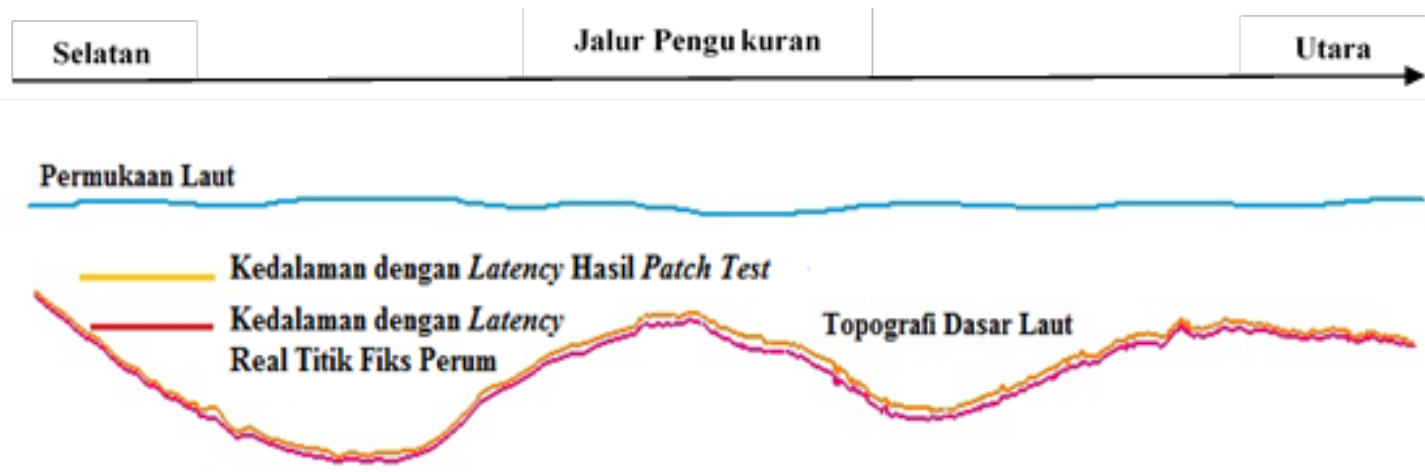

\section{Gambar 3. Tren Model Topografi Menggunakan Kecepatan Rata-rata 4,2 m/detik}

Berdasarkan Gambar 4.3 model topografi yang dibentuk oleh kedalaman yang diperoleh dari kedalaman hasil koreksi akibat latency hasil patch test pada sepanjang jalur pengukuran dan latency real titik fiks perum menggunakan kecepatan yang lebih rendah dengan rata-rata 4,2 m/detik di lokasi Tanjung Benoa, Bali secara keseluruhan tidak mengalami perbedaan yang signifikan, perbedaan kedalaman terbesar antara kedua teknik tersebut sebesar $0,81 \mathrm{~m}$ pada kedalaman $22 \mathrm{~m}$. Ratarata perbedaan kedalaman yang dibentuk pada model topografi dasar laut menggunakan kedua teknik tersebut adalah 0,09 m. Hal ini desebabkan pada jalur pengukuran ini menggunakan kecepatan yang lebih rendah sehingga informasi kedalaman yang diperoleh lebih detail dibandingkan dengan kecepatan yang lebih tinggi. Latency dan displacement yang terjadi di lokasi patch test Tanjung Benoa, Bali dilihat pada Tabel 2.

Tabel 2. Range Latency dan Displacement Untuk Dua Kecepatan Rata-rata 4,2 m/detik dan 6,2 m/detik

\begin{tabular}{ccc}
\hline Jenis Latency & Latency (detik) & Displacement (m) \\
\hline Patch Test & 0,20 & $0,460-1,180$ \\
\hline Latency Real Titik Fiks Perum & $0,00-0,25$ & $0,000-0,997$ \\
\hline
\end{tabular}

Berdasarkan Tabel 2 diketahui bahwa kesalahan latency di titik fiks perum terdapat nilai 0. Dengan demikian pengukuran posisi horizontal dan pengukuran kedalaman terjadi pada waktu yang sama, yang menyebabkan tidak terjadinya displacement. Menurut Lekkerkerk (2006) kesalahan akibat latency umumnya bernilai 0,2 hingga 1 detik dan kesalahan tersebut mengakibatkan kesalahan koordinat sebesar 0,3 hingga 5 meter, dengan kata lain pada bagian lokasi survei tersebut kesalahan latency sangat berpengaruh terhadap informasi kedalaman yang diperoleh karena jika terjadi displacement maka informasi kedalaman yang diperoleh akan berbeda dengan yang sebenarnya. Dari Tabel 4.2 latency real titik fiks perum yang terjadi mencapai 0,25 detik. Displacement yang terjadi sejauh 0,997 $\mathrm{m}$ untuk latency real titik fiks perum dan paling jauh 1,180 $\mathrm{m}$ akibat latency hasil patch test. 


\subsection{Korelasi}

Korelasi antara data kedalaman sepanjang jalur pengukuran hasil koreksi akibat latency menggunakan teknik patch test dan latency real titik fiks perum merupakan korelasi yang sangat kuat dengan nilai koefisien korelasi sebesar 0,99 yang menunjukkan hubungan data yang sangat kuat. Hal ini didukung oleh teori dari [Boediono, 2004] bila hasil koefisien korelasi $0,90<r<1,00$ atau $-1,00<r<-0,90$ artinya hubungan kedua data sangat kuat. Hasil kedalaman tersebut digambarkan dalam sumbu kartesian dengan Sumbu $X$ sebagai kedalaman hasil koreksi akibat latency hasil patch test dan Sumbu Y sebagai kedalaman hasil akibat latency real titik fiks perum. Korelasi antara dua data kedalaman hasil koreksi akibat latency pada jalur pengukuran yang menggunakan kecepatan yang lebih tinggi dengan rata-rata $6,2 \mathrm{~m} /$ detik seperti yang dapat dilihat pada Gambar 4.

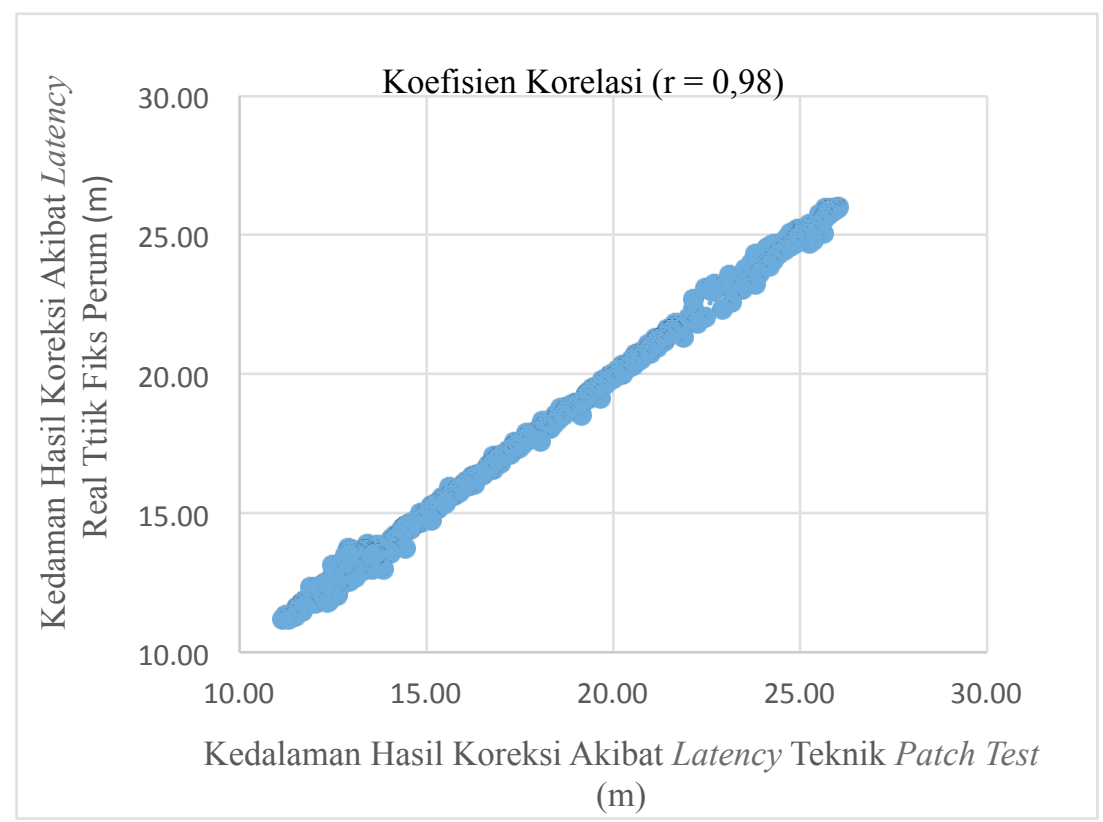

Gambar 4. Korelasi Data Kedalaman yang Menggunakan Kecepatan Rata-rata 6,2 m/detik

Berdasarkan Gambar 4 dapat dilihat bahwa korelasi data kedalaman pada jalur pengukuran kedalaman hasil koreksi akibat latency teknik patch test dengan kedalaman hasil koreksi akibat latency real titik fiks perum menunjukkan hubungan korelasi linier, hal tersebut didasarkan pada hasil plotting titik-titik kedalaman antara Sumbu X (kedalaman hasil koreksi akibat latency teknik patch test) dan Sumbu Y (kedalaman hasil koreksi akibat latency real titik fiks perum) pada sumbu kartesian mendekati pola garis lurus. Hasil kedalaman akibat koreksi latency menggunakan teknik patch test dan latency antar titik fiks perum pada jalur pengukuran tidak terlalu mengalami perbedaan yang signifikan, rata-rata perbedaan kedalaman hasil kedua teknik tersebut sebesar 0,14 m. Terdapat titik hasil koreksi kedalaman akibat latency menggunakan kedua teknik tersebut memiliki kedalaman yang sama atau dengan perbedaan terkecil sebesar $0 \mathrm{~m}$, sedangkan untuk perbedaan hasil kedalaman yang telah diberi koreksi akibat latency terbesar antara kedua teknik tersebut adalah 0,84 $\mathrm{m}$ pada kedalaman titik sebesar $13 \mathrm{~m}$. Sedangkan untuk korelasi data koreksi latency menggunakan teknik patch test dan latency real titik fiks 
perum pada jalur pengukuran menggunakan kecepatan rata-rata 4,2 $\mathrm{m}$ /detik dapat dilihat pada Gambar 5.

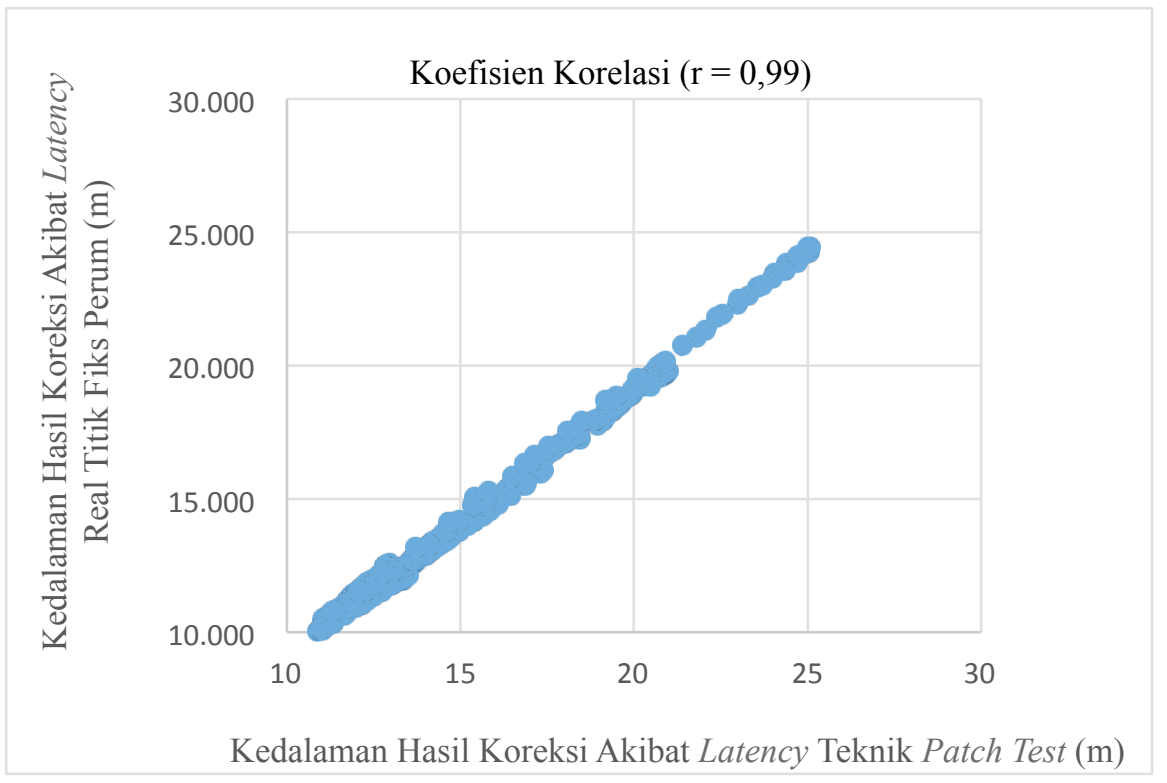

Gambar 5. Korelasi Data Kedalaman yang Menggunakan Kecepatan Rata-rata 4,2 m/detik

Berdasarkan Gambar 4.5 dapat dilihat bahwa korelasi data kedalaman pada jalur pengukuran antara hasil koreksi akibat latency teknik patch test dan kedalaman hasil koreksi akibat latency real titik fiks perum menunjukkan hubungan korelasi linier, hal tersebut didasarkan pada hasil plotting titik-titik kedalaman antara Sumbu $\mathrm{X}$ (kedalaman hasil koreksi akibat latency teknik patch test) dan Sumbu Y (kedalaman hasil koreksi akibat latency latency real titik fiks perum) pada sumbu kartesian mendekati pola garis lurus. Hasil koreksi akibat latency teknik patch test dan kedalaman hasil koreksi akibat latency antar titik fiks perum pada jalur pengukuran tidak terlalu mengalami perbedaan yang signifikan, rata-rata perbedaan kedalaman hasil kedua teknik tersebut sebesar $0,13 \mathrm{~m}$, sedangkan untuk perbedaan hasil kedalaman yang telah diberi koreksi akibat latency terbesar antara kedua teknik tersebut adalah 0,98 m pada kedalaman titik sebesar $12 \mathrm{~m}$. Perbedaan kedalaman hasil koreksi akibat latency yang diperoleh dari teknik patch test dan latency real titik fiks perum akan mempengaruhi model topografi yang dibentuk dan perbedaan informasi kedalaman yang akan digunakan.

\subsection{Deviasi Standar}

Deviasi Standar (simpangan baku) pada jalur pengukuran yang menggunakan dua jenis kecepatan menggunakan parameter perbedaan hasil kedalaman seluruh titik antara latency teknik patch test dan latency real titik fiks perum didapat nilai sebesar $\pm 0,2 \mathrm{~m}$ untuk jalur dengan kecepatan rata-rata $6,2 \mathrm{~m} /$ detik dan $\pm 0,16 \mathrm{~m}$ untuk jalur pengukuran dengan kecepatan rata-rata 4,2 m/detik. Menurut BSN (2010) standar ketelitian kedalaman di lokasi Pelabuhan Tanjung Benoa, Bali yang merupakan orde khusus memiliki nilai $\pm 0,28 \mathrm{~m}$. Dengan demikian ketelitian kedalaman untuk pengukuran di jalur patch test masih memenuhi standar baik untuk kecepatan lebih rendah maupun yang lebih tinggi. Nilai deviasi standar untuk jalur pengukuran 
menggunakan kecepatan dengan rata-rata $4,2 \mathrm{~m} /$ detik menunjukkan nilai yang lebih kecil dibandingkan dengan jalur pengukuran yang menggunakan kecepatan dengan rata-rata $6,2 \mathrm{~m} /$ detik. Hal tersebut menunjukkan bahwa penggunaan kecepatan yang lebih rendah memiliki perbedaan kedalaman hasil koreksi latency teknik patch test yang relatif tidak berbeda jauh dengan latency real titik fiks perum.

\section{KESIMPULAN}

Berdasarkan hasil penelitian mengenai perbandingan latency hasil patch test dengan latency real titik fiks perum pada survei hidrografi dengan lokasi yang digunakan untuk patch test di Pelabuhan Tanjung Benoa, Bali dapat disimpulkan bahwa lokasi tersebut memenuhi kriteria slope minimal $20^{\circ}$ seperti yang di tetapkan oleh Burnett (2013) pada topografi dasar lautnya. Lokasi ini memiliki slope rata-rata $23^{\circ}$. Tren model topografi hasil patch test dengan menggunakan kecepatan lebih rendah (ratarata 4,2 $\mathrm{m} /$ detik) dan kecepatan tinggi (rata-rata 6,2 $\mathrm{m} /$ detik) mewakili topografi dengan latency real di titik fiks perum ditunjukkan dengan nilai korelasi tinggi sebesar 0,99 dan 0,98. Tren model topografi hasil patch test dengan kecepatan yang lebih rendah (rata-rata 4,2 $\mathrm{m} /$ detik) lebih mewakili topografi dengan latency real di titik fiks perum. Hasil pengukuran menggunakan dua jenis kecepatan (rata-rata 4,2 $\mathrm{m} /$ detik dan 6,2 $\mathrm{m} /$ detik) masih memenuhi standar ketelitian kedalaman dalam SNI (BSN, 2010) sebesar $\pm 0,28 \mathrm{~m}$. Deviasi standar untuk kecepatan lebih rendah (ratarata 4,2 m/detik) sebesar $\pm 0,16 \mathrm{~m}$, sedangkan deviasi standar untuk kecepatan lebih tinggi (rata-rata $6,2 \mathrm{~m} /$ detik) sebesar $\pm 0,20 \mathrm{~m}$.

\section{UCAPAN TERIMA KASIH}

Penulis mengucapkan terima kasih kepada Sdr. Jimmy Dekha dalam kontribusinya menyediakan data pengukuran hasil patch test untuk keperluan proyek maintenance di Pelabuhan Tanjung Benoa Bali.

\section{DAFTAR PUSTAKA}

Badan Standardisasi Nasional (BSN) (2010). Survei Hidrografi Menggunakan Singlebeam Echosounder. SNI, Jakarta.

Boediono dan Koster, W. (2004). Teori dan Aplikasi: Statistika dan Probabilitas. Bandung: Remaja Rosdakarya.

Burnett, J. (2013). Multibeam System Setup and Patch Test Data Collection. United States of America: Hypack USA.

Lekkerkerk, H.J. (2006). Handbook of Offshore Surveying, Volume Two. Clarkson Research Services Ltd.

Razali, M., Gunathilaka, M.D.E.K, dan Wee, K. T. K. (2007). An Appraisal Of Multibeam Echosounder Calibration. Proceedings Of Joint International Symposium \& Exhibition On Geoinformation. Departement Of Geomatic Engineering, Universiti Teknologi Malaysia.

Seube, N., Levilly, S., dan Keyetieu-Nlowe, R. (2015). Automatic 3D Boresight and Latency Estimation of IMU and Multi-Beam Echo Sounder Systems. Proc. of the USHYDRO 15 Conf., 16-19 March, Washington DC, USA. 